\title{
Fluticasone Furoate: A Once Daily Preparation in Patients with Persistent Asthma
}

\author{
Paul A. Lilburn ${ }^{1 *}$, Henry Ainge-Allen', Paul S. Thomas ${ }^{1,2}$ \\ 'Department of Respiratory Medicine, Prince of Wales' Hospital, \\ 2Prince of Wales Clinical School and Mechanisms of Disease and Translational Research, Faculty of Medicine, University of New South Wales, NSW, Australia
}

Article Info

\section{Article Notes}

Received: September 2, 2018

Accepted: March 7, 2019

\section{*Correspondence:}

Dr. Paul A. Lilburn, Department of Respiratory Medicine,

Prince of Wales, Randwick, NSW, 2031, Australia;

Telephone No: +61 29382 24631; Fax No: +61 29382 4627;

Email: paul.lilburn@health.nsw.gov.au.

(c) 2019 Lilburn PA. This article is distributed under the terms of the Creative Commons Attribution 4.0 International License.
Abstract

Asthma affects approximately 240 million people worldwide. It is characterised by an allergic pattern of smooth muscle constriction and airway inflammation, and if chronic, the inflammation can lead to structural changes and fixed airflow obstruction. Bronchodilators relieve the bronchoconstriction, while inhaled corticosteroids reduce the airway inflammation. This paper reviews fluticasone furoate (FF), a novel inhaled corticosteroid with 24-hour duration of action. It is a synthetic fluorinated corticosteroid with agonist activity at the glucocorticoid receptor (GRE). It is reported to have a fast association and slow dissociation from the GRE compared to other ICSs. FF has been found to have a greater lung retention time than all other ICS preparations which may contribute to the extended duration of anti-inflammatory action. FF has extensive first pass hepatic metabolism resulting in a low gastrointestinal bioavailability which is consistent with the findings for other ICS preparations. $\mathrm{FF}$, however, will pass from the lung into the systemic circulation and therefore an adverse profile similar to all ICS is likely, but long term data are needed.

FF has demonstrated treatment efficacy for asthma between $100 \mu \mathrm{g}$ and $200 \mu \mathrm{g}$ alone, but in combination with the long-acting beta agonist, vilanterol (FF/VIL 200 $\mu \mathrm{g} / 50 \mu \mathrm{g}$ OD) there were further improvements in lung function relative to monotherapy. There is an increased risk of pneumonia identified in patients with airways disease in associated with ICS preparations and surveillance will be required to determine if this also applies to FF. Once daily therapy, such as FF, may improve compliance and could hopefully be translated into further improvements in asthma-related outcomes.

\section{Introduction}

Asthma is estimated to affect over 240 million people worldwide ${ }^{1}$. It is a heterogeneous disease, defined by symptoms which include wheeze, shortness of breath, chest tightness and cough. Asthma varies in intensity and over time, being characterised by variable expiratory airflow obstruction and inflammation.

Th2 asthma is caused characteristically by an allergic pattern of inflammation in the airways, involving initial sensitization to allergens, infiltration by antigen presenting cells such as dendritic cells, inflammatory cells (eosinophils and T-helper 2 (Th2) cells) and IgE priming of mast cells ${ }^{2,3,4}$. Less commonly, an alternate pathway has been described that can contribute to the development of low-Th2 asthma. These factors include infection-related elements, Th1 and Th17 immunity; non-Th2 associated smooth-muscle changes and the development of neutrophilic inflammation include hypertrophy and hyperplasia of airway smooth muscle cells, fibrosis, angiogenesis, and hyperplasia of mucus-secreting cells ${ }^{3,5}$. Chronic inflammation can lead to structural changes and fixed airflow obstruction. 
Oral corticosteroid therapy has proved efficacious for the treatment of asthma for many decades. To mitigate against some of the systemic side effects, inhalational therapy was a logical, effective solution. This coupled with the fact that asthma pathology is largely confined to the airways of the lungs has made inhaled corticosteroid (ICS) therapy the gold standard method for anti-inflammatory drug delivery ${ }^{6,7}$.

Glucocorticoids are the most effective anti-inflammatory treatment in asthma and switch off multiple activated pro-inflammatory genes ${ }^{8}$. Treatment with inhaled corticosteroids has been demonstrated, through histological specimens, to produce a reduction in mast cells, eosinophils, $\mathrm{T}$ lymphocytes and dendritic cells in the mucosa and submucosa; reduced goblet hyperplasia and epithelial-cell injury and decreased vascularity. However, neutrophilic inflammation is less likely to respond to ICS. No other drug class to date has demonstrated a greater effect in preventing adverse asthma-related outcomes than ICS ${ }^{9}$.

In those with poorly controlled asthma, it is estimated that this is due to poor adherence with preventative therapy in more than half of the patients, at least to some degree $^{10}$. Over-confidence and misuse of inhaled $\beta_{2}$ adrenergic therapy have also been shown to increase the risk of hospitalisation in asthmatics ${ }^{11,12}$.

Fluticasone furoate (FF) is a novel inhaled corticosteroid with 24-hour duration of action with proven efficacy morning and evening ${ }^{13}$. This paper reviews the literature supporting the use of FF as a once daily maintenance treatment of asthma in adults and adolescents over the age of 12 . A once daily inhaled corticosteroid could potentially improve compliance with medication and therefore reduce the risk of poor asthma-related outcomes associated with poor adherence $\mathrm{e}^{1,14}$.

\section{Structure}

The chemical composition of $\mathrm{FF}$ is $\mathrm{C}_{27} \mathrm{H}_{29} \mathrm{~F}_{3} \mathrm{O}_{6} \mathrm{~S}$ and is demonstrated below (Figure 1). It can be administered as a single agent via the inhalational route or in combination with a long acting $\beta_{2}$ - agonist (LABA) ${ }^{15}$. It is a synthetic fluorinated corticosteroid with agonist activity at the glucocorticoid receptor (GRE).

Fluticasone propionate (FP) is a well-established ICS for thetreatmentofasthma ${ }^{9}$. Although FFand FP are structurally related, they are chemically and pharmacologically distinct. They share no common metabolites nor are they metabolised to fluticasone, acting not as pro-drugs but as distinct drug molecules ${ }^{16}$. Differences between FF and FP were shown using x-ray crystallography demonstrating the ester derived from FF occupying a discreet pocket on the glucocorticoid receptor more fully than $\mathrm{FP}^{17}$. This suggests higher affinity of FF for both lung and nasal tissue ${ }^{18}$.

\section{Efficacy}

\section{Pre-clinical Studies}

The pharmacological properties of FF were examined in vitro and in vivo models of respiratory inflammatory disease (i.e. asthma and chronic obstructive pulmonary disease (COPD)). The potency of FF activity on the glucocorticoid response element (GRE) was examined

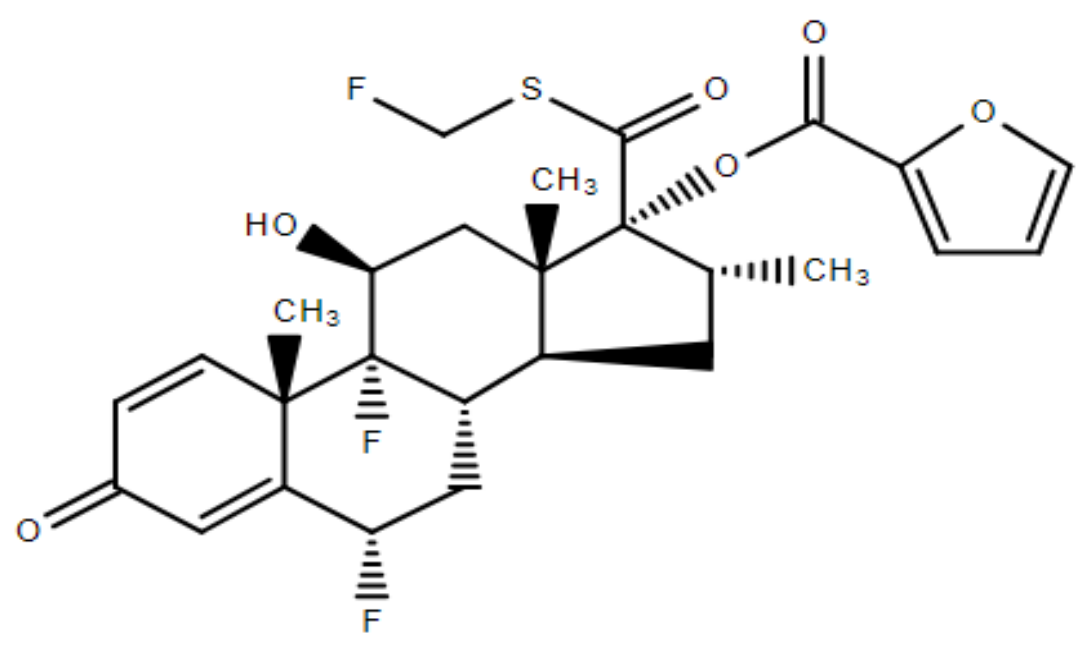

Figure 1: Fluticasone furoate $\left(\mathrm{C}_{27} \mathrm{H}_{29} \mathrm{~F}_{3} \mathrm{O}_{6} \mathrm{~S}\right)$ 


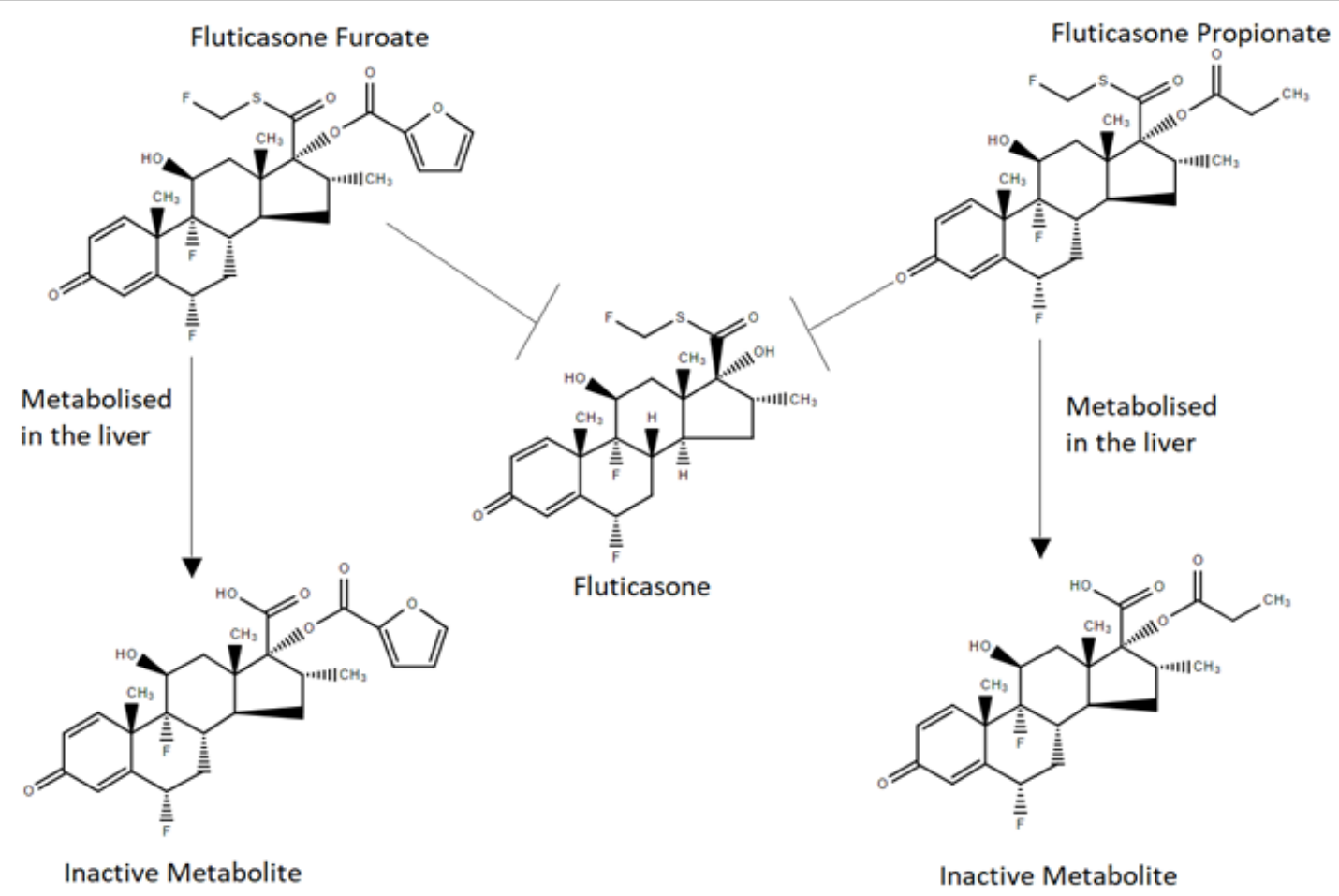

Figure 2: Structure of fluticasone furoate, fluticasone and fluticasone propionate and their major metabolites

and compared with other available ICS (e.g. mometasone furoate (MF); budesonide (BUD) and ciclesonide (CIC). The GRE is found in many target pro-inflammatory genes that respond to glucocorticoids. FF displayed the highest potency when compared with other corticosteroids tested by GRE binding, with a relative receptor affinity 1.7 times that of FP and 1.3 times that of MF. FF has also been shown to have increased affinity when compared to other available corticosteroids (dexamethasone and FP) on the GRE. MF demonstrated lower tissue binding compared with $\mathrm{FF}$ and $\mathrm{FP}^{19}$. FF has been found to be have greater lung tissue retention time than all other ICS preparations: FF > $\mathrm{MF} \geq \mathrm{FP}>$ triamcinolone acetonide (TAA) $>$ BUD $\geq$ (des-CIC) $>$ FLU $\geq$ Beclomethasone (BMP) ${ }^{20}$.

In an assay of lipopolysaccharide-stimulated tumour necrosis factor (TNF-alpha) release from peripheral blood mononuclear cells and transrepression nuclear factor- $\mathrm{kB}$ (NF-kB) reporter assays using a human lung epithelial cell line the anti-inflammatory effects of $\mathrm{FF}$ have been studied. Again, FF was compared with FP, MF, BUD and CIC. FF showed the highest potency of all the corticosteroids tested, with MF demonstrating a similarly high potency in the NF-kB assay. This study also demonstrated that FF had the largest cellular accumulation and the slowest rate of efflux relative to other clinically used glucocorticoids ${ }^{18}$. Additionally, in vitro, the rate of transport of FF out of the cells in the basal aqueous layer was slower than the other glucocorticoids, again consistent with retention of FF in respiratory tissues, which has been described. This is thought likely to contribute to an extended duration of anti-inflammatory action ${ }^{19}$.

\section{Clinical Research studies}

A Phase 0 study looking at metabolism and disposition of FF in 5 healthy male adults indicated systemic exposure from oral preparations had extensive first pass hepatic metabolism resulting in very low gastrointestinal bioavailability (recorded as $1.6 \%$ ) which is consistent with the findings for other ICS preparations ${ }^{21}$. Systemic availability of budesonide after oral administration was found to be approximately $10 \%{ }^{22}$. Interestingly, a study assessing the effect of systemic absorption of FP on adrenal glucocorticoid secretion via urinary cortisol in 28 asthmatic patients demonstrated that FP is likely to induce a decrease in nocturnal cortisol secretion in those with less severe airway obstruction, demonstrating variability of systemic bioavailability and possibly the effect being secondary to the amount of peripheral drug lung deposition in the target population ${ }^{23}$. No data have been published for FF in this regard.

The major route for metabolism of fluticasone furoate in humans is mediated primarily by Cytochrome P450 3A4 (CYP3A4). FF is converted by hydrolysis of the S-fluoromethyl carbthioate group to metabolites with significantly reduced corticosteroid activity. FF is also known to be a substrate of P-glycoprotein ${ }^{24}$. A repeat dose CYP3A4 drug interaction study was performed in healthy 
subjects with FF/VIL $(200 \mu \mathrm{g} / 25 \mu \mathrm{g})$ and a strong inhibitor of CYP3A4, ketoconazole $400 \mu \mathrm{g}$. The administration of both of these agents lead to an increase in the area under the curve $\left({ }_{0-24}\right)$ and maximal plasma concentration (Cmax) by $36 \%$ and $33 \%$ respectively. This subsequently led to a $27 \%$ reduction in serum cortisol, which could potentially lead to an increase in adverse events ${ }^{24}$. A Phase I study of FF and FP in 24 healthy male subjects showed the half-life (t1/2) for inhaled FF was longer than the estimated halflife for intravenous (IV) FF (17-24 h vs $14 \mathrm{~h}$, respectively), in contrast, the half-life for FP was similar whether inhaled or given intravenously (11 and $14 \mathrm{~h}$, respectively). This would suggest that FF is exhibiting absorption rate-limited pharmacokinetics following inhalation. The time for $90 \%$ absorption from the lung was also measured and found to be significantly longer for FF (20-30 h) than for FP (8 h), indicating a more prolonged lung retention time thus implying drug persistence with once-daily administration ${ }^{25}$.

A 24-week placebo and active-controlled randomised trial was undertaken in 2013. The authors concluded FF $100 \mu \mathrm{g}$ vs FP $250 \mu \mathrm{g}$ showed similar improvements in lung function vs placebo $\left(\mathrm{FEV}_{1}\right.$ pre-dose $+146 \mathrm{ml}[\mathrm{p}=0.009]$ and $+145 \mathrm{ml}[\mathrm{p}=0.011])^{26}$.

The followingyear, a 24-weekmulti-centre international, double blind, double dummy, parallel group Phase III study compared placebo vs FF $50 \mu \mathrm{g}$ and FP $100 \mu \mathrm{g}$ BD in 350 patients. This demonstrated that FF $50 \mu \mathrm{g}$ once daily dosing was not as effective as FP $100 \mu \mathrm{g}$ BD (evening trough $\mathrm{FEV}_{1}$ $+37 \mathrm{ml}[\mathrm{p}=0.43]$ and $+102 \mathrm{ml}[\mathrm{p}=0.03])^{27}$. The lower dose (50ug) is not commercially available as a consequence.

Investigation into differences between ethnicities has been undertaken with FF. Statistically significant differences in systemic absorption have been demonstrated between Caucasians and East Asian patients using both high dose $(800 \mu \mathrm{g})$ and low dose $(200 \mu \mathrm{g}) \mathrm{FF}$. Adjusting for weight East Asian compared with Caucasian subjects appeared to have FF retained in their lung for a longer duration 29.1-30.8hr vs $21.4 \mathrm{hr}$ respectively ${ }^{28}$. However, dose adjustments were deemed unnecessary because there had been no associated clinically significant effect on serum cortisol.

A study published in 2016 has also shown FF as an effective step-down agent from combination ICS/LABA to a single ICS monotherapy. A multicentre randomised control trial (RCT) assessed 430 Japanese asthma patients. This involved run in with ICS/LABA (FF/Vilanterol - VIL) in well-controlled asthmatics. This study demonstrated that step down to FF $100 \mu \mathrm{g}$ maintained similar control as compared with FP $100 \mu \mathrm{g}$ BD and FP $250 \mu \mathrm{g}$ BD with asthma control maintained at $89.5 \%$, compared with $78.2 \%$ and $83.1 \%$ respectively ${ }^{29}$. The study was not powered to detect treatment differences nor did the study mention if these differences were statistically significant.
In addition, the combination of FF/VIL has been examined. A Phase III study with both FF/VIL and FF alone demonstrated improvements in lung function relative to placebo at doses of $100 \mu \mathrm{g} / 25 \mu \mathrm{g}$, and $100 \mu \mathrm{g}$ respectively ${ }^{30}$. High doses of the vilanterol combination (FF/VIL 200 $\mu \mathrm{g} / 50 \mu \mathrm{g}$ OD) show significant improvements in lung function relative to FF $200 \mu \mathrm{g}$ OD and FP $500 \mu \mathrm{g} \mathrm{BD}$ with significant improvements in symptomatic end points compared with FF alone $(\mathrm{p}<0.001)$ and a trend towards a significant difference relative to $\mathrm{FP}(\mathrm{p}=0.067)$ in regards to rescue-free 24 hour periods ${ }^{31}$.

A systematic review assessed 31 studies and it concluded once daily FF/VIL was comparable with twice daily ICS/LABAs in improving lung function and patient reported symptom scores in asthmatics ${ }^{32}$. A similar review by Gray et al. concluded the FF/VIL combination demonstrated improvements in lung function and asthma control in addition to a similar side effect profile when compared with FP/salmeterol ${ }^{15}$.

Of interest, an observational study performed in 40 patients used a slightly lower dose of FF/VIL at 92/22 $\mu \mathrm{g}$ OD compared with BMP/formoterol (F) 100/6 $\mathrm{gg} \mathrm{BD}^{33}$. Significant improvements in asthma control and nocturnal symptoms, in addition to improved stability in lung function, were seen with $\mathrm{BMP} / \mathrm{F}^{33}$. Mean $\mathrm{FEV}_{1}$ in the $\mathrm{BMP} / \mathrm{F}$ group was found to be $78 \%$ at third visit and $79.1 \%$ at the final assessment compared with $74.5 \%$ and $75.8 \%$ in the FF/VIL group ${ }^{33}$, thus highlighting the importance of more robust head to head studies comparing different combination inhalers at equivalent commercially available doses.

FP has not demonstrated a clear dose-response curve with regards to lung function. A meta-analysis of seven studies in 2431 adolescents and adults with moderate to severe asthma demonstrated no therapeutic benefit of FP at doses higher than $200 \mu \mathrm{g} / \mathrm{day}^{34}$. FF has a similarly flat doseresponse curve. In an 8-week multicentre, randomised, double-blind Phase III study with 627 patients, incremental dosing of FF to $800 \mu \mathrm{g}$ did not show a dose relationship nor an improvement beyond $200 \mu \mathrm{g}$ for $\mathrm{FEV}_{1}$, but there were significant improvements above baseline ${ }^{35}$. budesonide, by comparison, has shown a dose-dependent response when using commercially available inhalers ${ }^{36,37}$. Single maintenance and reliever therapy (or 'SMART)' has been described with this ICS preparation in combination with the LABA, formoterol ${ }^{38}$.

FF has demonstrated clinical efficacy at both $100 \mu \mathrm{g}$ and $200 \mu \mathrm{g}$, which are now the commercially licensed inhaled doses $^{39}$. Patients were randomised to either $100 \mu \mathrm{g}$ or $200 \mu \mathrm{g} F$ and improvements in lung function were seen in both groups. Greater improvements in $\mathrm{FEV}_{1}$ with the higher dose were noted at week 24 , the end of the study period, however, this failed to reach significance $(77 \mathrm{ml} 95 \% \mathrm{CI}$ 
$-39,192)^{40}$. A similar study in 598 patients demonstrated a dose-response effect when comparing doses of $25 \mu \mathrm{g}, 50 \mu \mathrm{g}$, $100 \mu \mathrm{g}$ and $200 \mu \mathrm{g}$ FF. Significant increases in $\mathrm{FEV}_{1}$ were observed versus baseline for $50 \mu \mathrm{g}, 100 \mu \mathrm{g}$ and $200 \mu \mathrm{g} \mathrm{FF}$ which were clinically significant $(>200 \mathrm{ml})$ in the FF $100 \mu \mathrm{g}$ and $200 \mu \mathrm{g}$ arms $(\mathrm{p}<.05 \text { vs placebo })^{41}$.

The efficacy of once daily dosing compared with a twice daily regimen was also investigated. The higher dose of $200 \mu \mathrm{g}$ taken in the evening was compared with a $100 \mu \mathrm{g}$ BD regimen of FF. The study in 190 individuals demonstrated non-inferiority of once daily administration to twice a day dosing ${ }^{42}$. A further study randomised 575 individuals to one of four treatment arms of either placebo, $100 \mu \mathrm{g}$ in the morning or evening or a higher dose of $250 \mu \mathrm{g} \mathrm{FF}$. Completion rates were high, but lower, as expected, in the placebo arm. Significant improvements in lung function were demonstrated in all active treatment arms, combined with a reduction in asthma symptoms (difference in PEF vs placebo $19.2 \mathrm{~L} / \mathrm{min}, 15.9 \mathrm{~L} / \mathrm{min}$ and $24.6 \mathrm{~L} / \mathrm{min}$ respectively $[\mathrm{p}<0.001])$. All measures of symptoms - rescue medication, symptom-free nights \& days, met statistical significance $(\mathrm{p}<0.001)^{43}$.

An integrated safety and efficacy analysis study pooled data from 14 Phase II and Phase III studies and demonstrated FF efficacy compared with placebo ${ }^{44}$.

Despite MF having reportedly less specificity for the glucocorticoid receptor ${ }^{45}$, this ICS preparation has proved efficacious with once daily dosing also $^{46}$. No head to head comparisons of this or other ICS preparations with oncedaily FF have been undertaken.

\section{Adverse event profile}

FF has a low oral bioavailability due to limited absorption and extensive first pass metabolism, therefore any drug swallowed is thought unlikely to produce significant systemic side effects in most circumstances ${ }^{47}$. However, inhaled FF will pass from the lung into the systemic circulation and therefore an adverse profile similar to all ICS needs to be considered.

ICS related side effects are mainly due to either local deposition in the oropharynx or systemic absorption via the lung and the effect they have on the hypothalamicpituitary-axis (HPA). Studies to demonstrate the effect on the HPA largely involve screening tests demonstrating a reduction the 24-hour urinary cortisol (UC) or performing a 24-hour integrated measurement of plasma cortisol levels which are impractical and challenging to achieve in an outpatient setting ${ }^{48}$.

Due to these issues, the side effect profile of FF is routinely studied using the rates of oropharyngeal candidiasis and, as mentioned, a reduction in total 24-hour UC levels.
Oropharyngeal candidiasis demonstrates a dose dependent relationship with FF, occurring in $1 \%$ to $4 \%$ of patients taking doses up to $400 \mu \mathrm{g}^{35,43,49,50}$ which increases to $12 \%$ when inhaling $800 \mu \mathrm{g}$ FF per day ${ }^{35}$.

Urinary cortisol suppression has been reported for FF in a variable manner. No clinically significant difference in $24 \mathrm{hr}$ UC compared with placebo using doses up to $400 \mu \mathrm{g}$ OD has been seen $35,43,49,50$. However, doses at $800 \mu \mathrm{g}$ of FF vs placebo indicated UC suppression ${ }^{35}$. Daily doses of FF $200 \mu \mathrm{g}$ had statistically significant reductions of UC compared to placebo as did FP $100 \mu \mathrm{g}$ BD (ratio $0.75 \mathrm{p}<0.001$ and 0.84 $p=0.02$, respectively). No effects on urinary free-cortisol were recorded in the study ${ }^{42}$. Additionally, another study found similar suppression of UC relative to placebo with a lower dose of FF $100 \mu \mathrm{g}$ OD and a higher dose of FP $250 \mu \mathrm{g}$ $\mathrm{BD}^{26}$. Differences in the patient characteristics (e.g. weight, concurrent medication) would likely explain the variability seen as well as measurement methods between the studies.

Pooled data from 8 studies found no difference between FF and FP with respect to cortisol reduction in terms of clinically relevant doses $(100 \mu \mathrm{g} \& 200 \mu \mathrm{g})^{51}$.

Other potential long term adverse drug reactions and complications include osteoporosis, increased risk of mycobacterial infections, cataracts, hypertension, and diabetes mellitus are likely to occur. Currently, no direct data exist to further quantify the risk of these expected side effects with this drug versus the risks with other inhaled corticosteroids. FF is likely to be a more potent $\mathrm{ICS}^{19}$, and therefore extra care may need to be taken with the drug to avoid systemic side effects.

The well documented risk of ICS causing an increase in pneumonia in COPD patients by the TORCH ${ }^{52}$ and FLAME $^{53}$ studies provoked interest into whether this effect was translated in the asthmatic population. A Canadian study which identified 1928 pneumonia cases in over 150, 000 patients using ICS suggesting an increased risk of pneumonia associated with current use of ICS [RR 1.83; $95 \%$ confidence interval (CI) $1.57,2.14]^{54}$. To date there do not appear to be data to suggest that this signal has been investigated for FF. Further work is needed to assess risk in asthmatics, especially as the recent IMPACT ${ }^{55}$, Salford Lung Study ${ }^{56}$ and Summit ${ }^{57}$ studies all showed that COPD patients using an ICS, in these instances FF, was again associated with an increased pneumonia risk.

\section{Drug Delivery}

FF is inhaled using the ELLIPTA $®$ dry powder inhaler (DPI) device ${ }^{39}$. The ELLIPTA $®$ multi-dose inhaler has been developed for the delivery of inhaled medication in patients with airways disease with demonstrated efficacy at different flow rates $-30,60$ and $90 \mathrm{~L} / \mathrm{min}^{58}$. In addition, this device has been shown to be less prone to inhaler errors in patients with COPD $^{59}$. Both asthma and COPD 
patients also showed a preference to the ELLIPTA $®$ DPI device when compared with the other inhalation devices tested ${ }^{59}$.

\section{Discussion}

Fluticasone furoate is a novel inhaled corticosteroid with a long lung retention time and fast association and slow dissociation from the glucocorticoid receptor compared to other ICS ${ }^{19}$. Thomas and colleagues demonstrated that either evening or morning doses of FF at a dose of $100 \mu \mathrm{g}$ produced similar improvements in lung function compared with placebo ${ }^{13}$. The pharmacological profile of $\mathrm{FF}$ has been demonstrated in multiple preclinical and clinical studies with 24-hour duration of action, making it an acceptable option for once daily dosing.

$\mathrm{FF}$ has demonstrated non-inferiority to $\mathrm{FP}$ and is therefore an alternative to this ICS twice daily medication. Budesonide and mometasone may be more desirable ICS preparations given the fact that FF, like FP, has not been demonstrated to have a dose-response effect. Nevertheless, FF at low dose has demonstrable efficacy and could be used for many patients with persistent asthma uncontrolled by short acting $\beta 2$-agonists alone, and the lowest effective dose should be used in accordance with the GINA guidelines ${ }^{1}$. In addition, $\mathrm{FF}$ has not been identified as a candidate for 'SMART' therapy in asthmatics, used with other ICS preparations.

Further studies are required investigating the comparison of FF versus the other ICS drugs currently available. FF appears to show improved specificity compared with MF with regards to the GRE, this and the long lung retention may support once daily ICS preparation. MF has shown improved adherence with once daily dosing ${ }^{46}$. A large Cochrane review was undertaken in $2010^{60}$ which compared multiple different ICS preparations, but unfortunately since the introduction of FF no large scale meta-analysis or RCT has been undertaken comparing FF with other ICS.

Currently, its side effect profile does not present additional concern that would lead physicians to consider the medication more hazardous than other ICS preparations but with a long retention time, other side effects may be recognised later. Adverse effects including oropharyngeal candidiasis and adrenal suppression are likely to be associated with higher doses of FF. The FF adverse profile appears similar to other ICS preparations. There is an increased risk of pneumonia identified in patients with airways disease with the use of some ICS preparations and as it is likely to be a class effect, this will need to be observed in large scale studies to identify whether FF also demonstrates this signal.

It is recognised that personality traits and beliefs about medicine will directly affect adherence to asthma treatment, however, ease of administration also plays a significant role ${ }^{61}$. Once daily therapy, such as FF could hopefully be translated into further improvements in asthma-related outcomes in the future, however, to date the evidence for this over twice daily dosing is currently lacking.

\section{Conflict of interests}

Professor Paul S. Thomas has been a principal investigator for trials in asthma on behalf of GSK and Astra Zenenca.

\section{References}

1. Global Initiative for Asthma. Global Strategy for Asthma Management and Prevention. 2017. [online] Available at: http://ginasthma.org/ wp-content/uploads/2016/04/GINA-2016-main-report_tracked.pdf [Accessed $4^{\text {th }}$ Apr. 2017].

2. Barnes PJ. Immunology of asthma and chronic obstructive pulmonary disease. Nat Immunol Re. 2008; 8(3): 183-192.

3. Earl CS, An SQ, Ryan RP. The changing face of asthma and its relation with microbes Trends in Microbiology. 2015; 23( 7): 408-418.

4. Hamid Q, Tulic M. Immunobiology of asthma. Annu Rev Physiol. 2009; 71: 489-507.

5. Barnes PJ. The cytokine network in asthma and chronic obstructive pulmonary disease. J Clin Invest. 2008; 118: 3546-56.

6. Barnes P. Biochemical basis of asthma therapy. J Biol Chem. 2011; 286(38): 32899 - 32905.

7. Montuschi P, Barnes PJ. New perspectives in pharmacological treatment of mild persistent asthma. Drug Discov Today. 2011; 16(2324): 1084-91.

8. Barnes PJ. Mechanisms and resistance in glucocorticoid control of inflammation. J Steroid Biochem Mol Biol. 2010; 31; 120(2-3): 76-85.

9. Fanta CH. Asthma, drug therapy NEJM. 2009; 360; 10: 1002- 1014.

10. Partridge MR, van der Molen T, Myrseth SE, et al. Attitudes and actions of asthma patients on regular maintenance therapy: the INSPIRE study. BMC Pulm Med. 2006; 6: 13.

11. Chapman KR, Boulet LP, Rea RM, et al. Suboptimal asthma control: prevalence, detection and consequences in general practice. Eur Respir J. 2008; 31: 320-5.

12. van Ganse E, Hubloue I, Vincken W, et al. Actual use of inhaled corticosteroids and risk of hospitalisation: a case-control study. Eur J Clin Pharmacol. 1997; 51(6): 449-54.

13. Kempsford RD, Bal J, Baines A, et al. Efficacy of fluticasone furoate administered in the morning or evening is comparable in patients with persistent asthma Resp Medicine. 2016; 112: 18-24.

14. Williams LK, Pladevall M, Xi H, et al. Relationship between adherence to inhaled corticosteroids and poor outcomes among adults with asthma. J Allergy Clin Immunol. 2004; 114(6): 1288-93.

15. Gray EL, Chang V, Thomas PS. Fluticasone furoate and vilanterol combination therapy for the treatment of asthma Exp. Rev of Resp Med. 2016; 10(8): 839-847.

16. Biggadike K. Fluticasone furoate/fluticasone propionate - different drugs with different properties The Clinical Respiratory Journal. $2011 ; 183-184$.

17. Biggadike K, Bledsoe RK, Hassell AM, et al. X-ray crystal structure of the novel enhanced-affinity glucocorticoid agonist fluticasone furoate in the glucocorticoid receptor-ligand binding domain. J Med Chem. 2008; 51(12): 3349-52. 
18. Salter M, Biggadike K, Matthews JL, et al. Pharmacological properties of the enhanced-affinity glucocorticoid fluticasone furoate in vitro and in an in vivo model of respiratory inflammatory disease. Am J Physiol Lung Cell Mol Physiol. 2007; 293(3): L660-7.

19. Valotis A, Hogger P. Human receptor kinetics and lung tissue retention of the enhanced-affinity glucocorticoid fluticasone furoate. Respir Res. 2007; 8: 54.

20. Daley-Yates PT. Inhaled corticosteroids: potency, dose equivalence and therapeutic index. Br J Clin Pharmacol. 2015; 80(3): 372-380.

21. Hughes S, Shardlow P, Hollis F, et al. Metabolism and Disposition of fluticasone furoate, an Enhanced-Affinity Glucocorticoid, in Humans. Drug Metab Dispos. 2008; 36(11): 2337-44 .

22. Jonsson G, Astrom A, Andersson P. Budesonide is metabolized by cytochrome P450 3A (CTP3A) enzymes in human liver. Drug Metab Dispos. 1995; 23(1): 37-42.

23. Weiner P, Berar-Yanay N, Davidovich A, et al. Nocturnal cortisol secretion in asthmatic patients after inhalation of fluticasone propionate. Chest. 1999 Oct; 116(4): 931-4.

24. Kempsford R, Allen A, Bal J, et al. The effect of ketoconazole on the pharmacokinetics and pharmacodynamics of inhaled fluticasone furoate and vilanterol trifenatate in healthy subjects. British Journal of Pharmacology. 2012; 75: 6 1478-1487.

25. Allen A, Bareille PJ, Rousell VM. Fluticasone furoate, a novel inhaled corticosteroid, demonstrates prolonged lung absorption kinetics in man compared with inhaled fluticasone propionate. Clin Pharmacokinet. 2013; 52: 37-42.

26. Lotvall J, Bleecker ER, Busse WW, et al. Efficacy and safety of fluticasone furoate $100 \mu \mathrm{g}$ once-daily in patients with persistent asthma: A 24-week placebo and active-controlled randomised trial. Respir Med. 2014; 108(1): 41-9.

27. Busse WW. Once daily fluticasone furoate $50 \mathrm{mcg}$ in mild-to-moderate asthma: a 24 week placebo-controlled randomised trial Allergy. 2014; 69: 1522-1530.

28. Allen A, Bal J, Cheesbrough A, et al. Pharmacokinetics and pharmacodynamics of intravenous and inhaled fluticasone furoate in healthy Caucasian and East Asian subjects. Brit J Clin Pharmacol. 2014; 77(5): 808-20.

29. Adachi M, Goldfrad C, Jacques L, et al. Efficacy and safety comparison: fluticasone furoate and fluticasone propionate, after step down from fluticasone furoate/vilanterol in Japanese patients with wellcontrolled asthma, a randomized trial. Respir Med. 2016; 120: 78-86.

30. Bleecker ER. Fluticasone furoate-vilanterol 100/25g compared with fluticasone furoate $100 \mathrm{~g}$ in asthma: a randomised trial. J Allergy Clin Immunol Pract. 2014; 2(5): 553-561.

31. O’Byrne PM, Bleecker ER, Bateman ED, et al. Once-daily fluticasone furoate alone or combined with vilanterol in persistent asthma Eur Respir J. 2014; 43: 773-782.

32. Svedsater H, Stynes G, Wex J, et al. Once-daily fluticasone furoate/ vilanterol versus twice daily combination therapies in asthma-mixed treatment comparisons of clinical efficacy Asthma Research and Practice. 2016; 2: 4.

33. Terzano C, Oriolo F. Fluticasone furoate/Vilanterol 92/22g once-aday vs Beclomethasone dipropionate/Formoterol 100/6g b.i.d. in asthma patients: a 12-week pilot study J Pulmonary Respir Res. 2017; 1: 013-022.

34. Masoli M, Weatherall M, Holt S, et al. Clinical dose-response relationship of fluticasone propionate in adults with asthma Thorax. 2004; 59: 16-20.

35. Busse WW, Bleecker ER, Bateman ED, et al. Fluticasone furoate demonstrates efficacy in patients with asthma symptomatic on medium doses of inhaled corticosteroid therapy: an 8-week, randomised, placebo-controlled trial. Thorax. 2012; 67(1): 35-41.

36. Masoli M, Holt S, Weatherall M, et al. Dose response relationship of inhaled budesonide in adult asthma: a meta-analysis Eur Respir J. 2004; 23: 552-558.

37. Busse WW, Chervinsky P, Condemi J, et al. Budesonide delivered by Turbuhaler is effective in a dose-dependent fashion when used in the treatment of adult patients with chronic asthma. J Allergy Clin Immunol. 1998; 101: 457-463.

38. Kew KM. Cochrane review: Combination formoterol and budesonide as maintenace and reliever therapy (SMART regimen) for chronic asthma. Cochrane Database of Systematic Reviews 2013 Issue 12.

39. GlaxoSmithKline. (2016) Arnuity Ellipta highlights of prescribing. Retrieved from https://www.accessdata.fda.gov.drugsatfda.docs/ label/2014/205625s000lbl.pdf (accessed 28/7/18)

40. Woodcock A, Lötvall J, Busse WW, et al. Efficacy and safety of fluticasone furoate $100 \mathrm{mcg}$ and $200 \mathrm{mcg}$ once daily in the treatment of moderate-severe asthma in adults and adolescents: a 24-week randomised study BMC Pul Med. 2014; 14: 113.

41. Bateman ED, Bleecker ER, Lötvall J, et al. Dose effect of once daily fluticasone furoate in persistent asthma: A randomized trial Res Med. 2012; 106: $642-650$

42. Woodcock A, Bleecker ER, Busse WW, et al. Fluticasone furoate: Oncedaily evening treatment versus twice-daily treatment in moderate asthma. Respir Res. 2011; 12: 160.

43. Medley H, Orozco S, Allen A. Efficacy and safety profile of fluticasone furoate administered once daily in the morning or evening: A randomised, double-blind, double-dummy, placebo-controlled trial in adult and adolescent patients with persistent bronchial asthma. Clinical Therapeutics. 2012; 34(8): 1683-95.

44. O'Byrne PM, Jacques L, Goldfrad C, et al. Integrated safety and efficacy analysis of once-daily fluticasone furoate for the treatment of asthma Respir Res. 2016; 17: 157.

45. Austin RJ, Maschera B, Walker A, et al. Mometasone furoate is a less specific glucocorticoid than fluticasone propionate Eur Respir J. 2002; 20: $1386-1392$

46. Price D, Robertson A, Bullen K, et al. Improved adherence with oncedaily versus twice-daily dosing of mometasone furoate administered via a dry powder inhaler: a randomized open-label study $B M C$ Pulmonary Medicine. 2010; 10: 1.

47. Lipworth BJ. Systemic adverse effects of inhaled corticosteroid therapy Arch Intern Med. 1999; 159(9): 941-955. doi:10.1001/ archinte.159.9.941

48. Lipworth BJ, Seckl JL. Measures for detecting systemic bioactivity with inhaled and intranasal corticosteroids. Thorax. 1997; 52476- 482.

49. Woodcock A, Bateman ED, Busse WW, et al. Efficacy in asthma of oncedaily treatment with fluticasone furoate: A randomised, placebocontrolled trial. Respir Res. 2011; 12: 132.

50. Bleecker ER, Bateman ED, Busse WW, et al. Once daily fluticasone furoate is efficacious in patients with symptomatic asthma on low dose inhaled corticosteroids. Ann Allergy Asthma Immunology. 2012; 109(5): 353 -358.

51. Allen A. The Relationship between Ffluticasone furoate systemic exposure and cortisol suppression. Clin Pharmacokinet. 2013; 52: 885-896.

52. Calverley PM, Anderson JA, Celli B, et al. Salmeterol and fluticasone propionate and survival in chronic obstructive pulmonary disease. $\mathrm{N}$ Engl J Med. 2007; 356: 775-789.

53. Wedzicha JA, Banerji D, Chapman KR, et al. Indacaterol-glycopyronium versus salmeterol fluticasone for COPD. N Engl J Med. 2016; 374: 2222-2234 
54. Qian CJ, Coulombe J, Suissa S, et al. Pneumonia risk in asthma patients using inhaled corticosteroids: a quasi-cohort study. Br J Clin Pharmacol. 2017; 83(9): 2077-2086.

55. Lipson DA, Barnhart F, Brealey N, et al. Once-daily single-inhaler triple versus dual therapy in patients with COPD. N Engl J Med. 2018; 378: $1671-1680$.

56. Albertson TE, Murin S, Sutter ME, et al. The Salford Lung Study: a pioneering comparative effectiveness approach to COPD and asthma in clinical trials. Pragmat Obs Res. 2017 Sep 20; 8: 175-181.

57. Vestbo J, Anderson JA, Brook RD, et al. Fluticasone furoate and vilanterol and survival in chronic obstructive pulmonary disease with heightened cardiovascular risk (SUMMIT): a double-blind randomised controlled trial The Lancet. 2016; 387: 1817 -1826.

58. Grant AC, Walker R, Hamilton M, et al. The ELLIPTA® Dry Powder
Inhaler: Design, functionality, In Vitro Dosing Performance and Critical Task Compliance by Patients and Caregivers. Journal of Aerosol Medicine and Pulmonary Drug Delivery. 2015; 28(6): 474-85.

59. van der Palen J, Thomas M, Chrystyn H, et al. A randomised open-label cross-over study of inhaler errors, preference and time to achieve correct inhaler use in patients with COPD or asthma: comparison of ELLIPTA with other inhaler devices. Primary Care Respiratory Medicine. 2016 Nov 24; 26: 16079.

60. Adams N, Lasserson TJ, Cates CJ, et al. Fluticasone versus beclomethasone or budenoside for chronic asthma in adults and children. (Review) Cochrane Database of Systematic reviews. 2010 Issue 4.

61. Emilsson M, Berndtsson I, Lötvall J, et al. The influence of personality traits and beliefs about medicines on adherence to asthma treatment Primary Care Respiratory Journal. 2011; 20(2): 141-147. 